

\title{
Influence of prestrain on the numerical simulation of the roller hemming process
}

\author{
Nicolas Le Maoût, Pierre-Yves Manach, Sandrine Thuillier
}

\section{To cite this version:}

Nicolas Le Maoût, Pierre-Yves Manach, Sandrine Thuillier. Influence of prestrain on the numerical simulation of the roller hemming process. Journal of Materials Processing Technology, 2012, 212 (2), pp.450-457. 10.1016/j.jmatprotec.2011.10.008 . hal-00715740

\section{HAL Id: hal-00715740 \\ https://hal.science/hal-00715740}

Submitted on 5 Feb 2019

HAL is a multi-disciplinary open access archive for the deposit and dissemination of scientific research documents, whether they are published or not. The documents may come from teaching and research institutions in France or abroad, or from public or private research centers.
L'archive ouverte pluridisciplinaire HAL, est destinée au dépôt et à la diffusion de documents scientifiques de niveau recherche, publiés ou non, émanant des établissements d'enseignement et de recherche français ou étrangers, des laboratoires publics ou privés. 


\title{
Influence of prestrain on the numerical simulation of the roller hemming process
}

\author{
N. Le Maoût, P.Y. Manach*, S . Thuillier \\ LIMATB, Université Europénne de Bretagne, Université de Bretagne-Sud, BP 92116, 56321 Lorient, France
}

\begin{abstract}
This study focuses on the numerical simulation of roller hemming of an aluminium alloy sample with a curved geometry; this non-planar geometry is obtained by a prestrain procedure similar to deep drawing process. Material characterization was performed through tensile and simple shear tests at different orientations on the sheet plane. The influence of considering the Bauschinger effect, anisotropy, and the strain history on the final geometry was studied. A specific laboratory device for roller hemming was designed to forward an experimental database. The numerical simulation of the roller hemming of these samples is presented here, as well as the correlation between the calculations and the experimental tests, notably the roll-in value and the prediction of wrinkling.
\end{abstract}

\section{Introduction}

Opening parts of automobiles are generally made of a reinforcing inner part and an outer part (skin), which are both deep drawn, glued, and assembled by hemming, as is described for example by Iwata et al. (1995). Hemming, an alternative to traditional assembly processes like welding, is a three-step process (Livatyali et al., 2000) which can be performed with specific dies and blades (classical hemming) or with a robot and a roller (roller hemming). These technologies have greatly evolved in recent years. In fact, industries are phasing out expensive technologies, such as classical hemming, and opting for roller hemming, a technology which uses lighter equipment and for which tool development is more flexible and which employs a handling robot. Usage of this new process is quite recent and there is only limited information available from the experiments of specialists; however, its numerical simulation was developed not so long ago (Thuillier et al., 2008). Therefore, numerical simulation of this process will still demand some time and several hypotheses on sheet behavior under the roller (appearance of wrinkling, roll-in value, etc.) should be investigated. Like for classical hemming, numerical modeling should provide insight into the geometry of opening parts, which should be adopted to avoid hemming feasibility problems.

The research works of Thuillier et al. (2008) focus on the finite element simulation of the roller hemming process for an $\mathrm{Al}-\mathrm{Mg}$ alloy. The sample is planar and has a convex edge. Particular attention is paid to the influence of the behavior models have on the

\footnotetext{
* Corresponding author.

E-mail address: pierre-yves.manach@univ-ubs.fr (P.Y. Manach).
}

numerical predictions and the results are compared to those of classical hemming for the same geometry. The results for both processes show different evolutions of the plastic strain and the roll-in. The study carried out by Li et al. (2011) presents a similar study on a simpler geometry (planar straight-edged sample), but compares the numerical results to the experimental results. The results correspond to those of previous studies and show better testing correlation when considering the Bauschinger effect. The samples, however, are not prestrained and are, therefore, not representative of the industrial process in which pieces first undergo deep drawing. It is important to take prestrain into account because it affects the final geometry and can cause damage during classical hemming for steels (Le Maoût et al., 2009), for aluminium alloys (Thuillier et al., 2011), as well as during roller hemming (Hu et al., 2010).

This article is devoted to the numerical simulation of the roller hemming of a curved piece, which has undergone prestrain equivalent to that of an opening part of an automobile after deep drawing. The numerical modeling of the process is developed in a finiteelement code and the results obtained for this particular geometry are then presented. The influence of the material model and of the preliminary hemming steps is also studied. Finally, the numerical prediction is compared to the experimental results gathered through a specific experimental set-up for hemming.

\section{Material and identification}

A 6000 series aluminium alloy is focused on here, which is widely used in the automobile industry for the visible body parts of vehicles. Its main additional elements are magnesium and silicium, the chemical composition being given in Table 1 . 
Table 1

Chemical composition in weight \% of aluminium alloy AA6016.

\begin{tabular}{|c|c|c|c|c|c|c|c|c|c|}
\hline $\mathrm{Al}$ & Mg & $\mathrm{Si}$ & $\mathrm{Cr}$ & Mn & $\mathrm{Cu}$ & $\mathrm{Ti}$ & $\mathrm{Fe}$ & $\mathrm{Zn}$ & Others \\
\hline $96.4-98.8$ & 0.25 & $1.0-1.5$ & $\leq 0.1$ & $\leq 0.2$ & $\leq 0.2$ & $\leq 0.15$ & $\leq 0.5$ & $\leq 0.2$ & $\leq 0.2$ \\
\hline
\end{tabular}

To describe the behavior of this aluminium alloy, Hill's 1948 yield criterion (Hill, 1948) is used to represent the material anisotropy. This choice is in accordance with the conclusions of previous studies (Svensson and Mattiason, 2002), on the pertinence of the various yield surfaces applied to numerical simulation of hemming process. Mixed hardening is also used, the kinematic contribution of which is non-linear and of the Armstrong and Frederick (1966) type. In this case, the yield function $\phi$ is written as:

$\phi(\boldsymbol{\sigma}, \boldsymbol{X}, R)=\sqrt{\frac{3}{2}(\boldsymbol{S}-\boldsymbol{X}): \boldsymbol{H}:(\boldsymbol{S}-\boldsymbol{X})}-\sigma_{0}-R$

where $\sigma_{0}$ is the yield stress in tension in the rolling direction (RD), $\boldsymbol{S}$ is the deviatoric part of the Cauchy stress tensor $\boldsymbol{\sigma}$, and $\boldsymbol{H}$ is the fourth-order Hill's tensor which takes into account the orthotropic symmetry of the material. It depends on coefficients: $F, G, H, L, M$ and $N$ among which $F, G, N$ are identified at the same time as all parameters of the hardening model. The following classical hypothesis are made: $L=M=3$ and $H+G=2$. Variable $R$ of Eq. (1) is a scalar describing isotropic hardening and $\boldsymbol{X}$ a second-order tensor which describes kinematic hardening. The evolution of $\boldsymbol{X}$ is:

$\dot{\boldsymbol{X}}=Q_{\mathrm{x}} \dot{\boldsymbol{\epsilon}}^{p}-b_{\mathrm{X}} \boldsymbol{X} \dot{p}$

$b_{\mathrm{x}}$ represents the hardening saturation rate, $Q_{\mathrm{x}}$ is the saturation value, $p$ the cumulated plastic strain and $\dot{\boldsymbol{\epsilon}}^{p}$ the plastic strain rate tensor. Three models are studied, the first uses a mixed hardening with a saturated isotropic hardening of the Voce type (Lange et al., 2005) (Hill48-Mixed model):

$R=Q[1-\exp (-b p)]$

$Q$ represents the maximum change of the yield surface size, while $b$ defines the growth rate of the yield surface. The second model uses isotropic hardening with an anisotropic yield surface to highlight the influence of the Bauschinger effect on the load and roll-in results (Hill48-Iso model). Finally, the third model only uses a Voce type isotropic hardening with an isotropic yield surface (Mises-Iso model).

Several types of mechanical tests were carried out to determine the material parameters through a process set forth in detail in Gallée et al. (2007). Tensile tests were carried out on rectangular samples, the useful surface of which is $140 \mathrm{~mm} \times 20 \mathrm{~mm}$. A series of tests were done on orientations of $0^{\circ}, 45^{\circ}$ and $90^{\circ}$ to RD to determine the plastic anisotropy ratios (Figs. 1a and 2 ). The tests were carried out till failure with a strain rate of $\dot{\epsilon}=10^{-3} \mathrm{~s}^{-1}$. To measure the parameters linked to the kinematic hardening component, simple shear tests were done according to the method described by Thuillier and Manach (2009) on samples with a useful area of $50 \mathrm{~mm} \times 4.5 \mathrm{~mm}$. Both monotonic and alternating tests were performed, after a prestrain of $\gamma=0.1$ and 0.2 , in the RD (Fig. 1b). Finally, parameter identification was carried out through an inverse method using SiDoLo (Chaparro et al., 2008); the parameter values thus obtained are given in Table 2 .

As has been noted here, the retained models enable good representation of flow stress, as well as tensile and shear stress for the various orientations for monotonic loading. The alternating shear tests, presented in Fig. 1b, highlight the necessity of taking the kinematic hardening component into account. Finally, the use of Hill's 1948 yield criterion for this material does not provide a satisfying description of plastic anisotropy ratio evolution for various orientations. In fact, this is in correlation with Bochud et al. (2008), who proved that is was often difficult to correctly represent both the stress level and the transverse strain with the same set of parameters for this yield criterion.

\section{Experimental investigation}

The hemming sample of thickness $1 \mathrm{~mm}$ is characterized by a curved surface of radius $S_{s t}=215 \mathrm{~mm}$ and a hemming edge of radius $E_{s h}=258 \mathrm{~mm}$, see Fig. 3a. Radius $S_{s t}$ is obtained through sample prestrain done before the flanging and hemming steps. Different types of car opening parts (doors, hoods, and deck lids) have been analyzed in such a way as to determine the value of radius $S_{s t}$ to come as close as possible to industrial cases in terms of geometry and prestraining. Sample length was chosen to be $160 \mathrm{~mm}$, so as to avoid edge effects while facilitating their placement in the tools. The edge radius value $E_{s h}$ is close to the value used on the planar samples studied in Lange (2008), also representative of the radii often found in the opening parts of automobiles.

The hemming process generates a modification in the final dimensions of the assembly which is difficult to anticipate. This phenomenon, called roll-in, may be considered as a defect as it significantly modifies the esthetics of the vehicle, see Fig. 4. This dimensional reduction, which happens between the flanging and pre-hemming steps, requires the measuring of the evolution of the position of the hemmed edge during each step. To do so, roll-in is measured for several sections of the sample defined in Fig. 3b along a concentric circle to the radius $E_{s h}$, the one at $0^{\circ}$ corresponds to $\mathrm{RD}$. The measurements for the flanging height as well as the roll-in reference, are given in Fig. 3c. Roll-in is calculated using the distance between the points ( $1 \mathrm{st}$ point and 2 nd point at $4 \mathrm{~mm}$ from the surface) as a reference during flanging. For the pre-hemming, and hemming steps, the second point is the one farthest away in the bent zone. Roll-in corresponds to the difference between the flanging measurement and the pre-hemming and hemming measurements.

A biaxial expansion set up similar to the one developed by Grolleau et al. (2008) is used to obtain the curved surface. The value $S_{s t}$ of the curved surface is obtained by monitoring the three displacement points during the test (Fig. 5a). The geometry of the hemming samples with an in-plane radius $E_{s h}$ is finally produced by laser trimming (Fig. $5 \mathrm{~b}$ ). It should be noted that the radius $E_{s h}$ of the inner part is smaller so that it may be set back from the edge of the skin part. A hemming set up was designed and realized to flange and hem prestrained samples. This device, the characteristics of which are given by Le Maoût et al. (2010), can be adapted onto a tensile testing machine of $500 \mathrm{kN}$ capacity in order to flange the outer skin samples. The flanged samples are then placed in the pre-hemming die in such a way that makes them flush with the tool edge (Fig. $5 \mathrm{c}$ ) and both the inner and the outer skins are tightened under a pressure of $8.9 \mathrm{MPa}$, eliminating any geometric deviation from the biaxial prestrain. The flanged height is around $9 \mathrm{~mm}$ and the flanging radius is set to $2 \mathrm{~mm}$ for this material. Roller hemming is then carried out. Kinematics of the roller are imposed by a handling robot. A $47 \mathrm{~mm}$ cylindrical roller is mounted on a ball bearing thus giving it free rotation on its revolution axis. A sensor, placed above the roller, registers the compressive loads applied according to the direction of the robot arm. The robot trajectory is set so that the arm is constantly normal to the die surface edge with a pre-hemming angle of $50^{\circ}$ and the linear speed of the roller is 

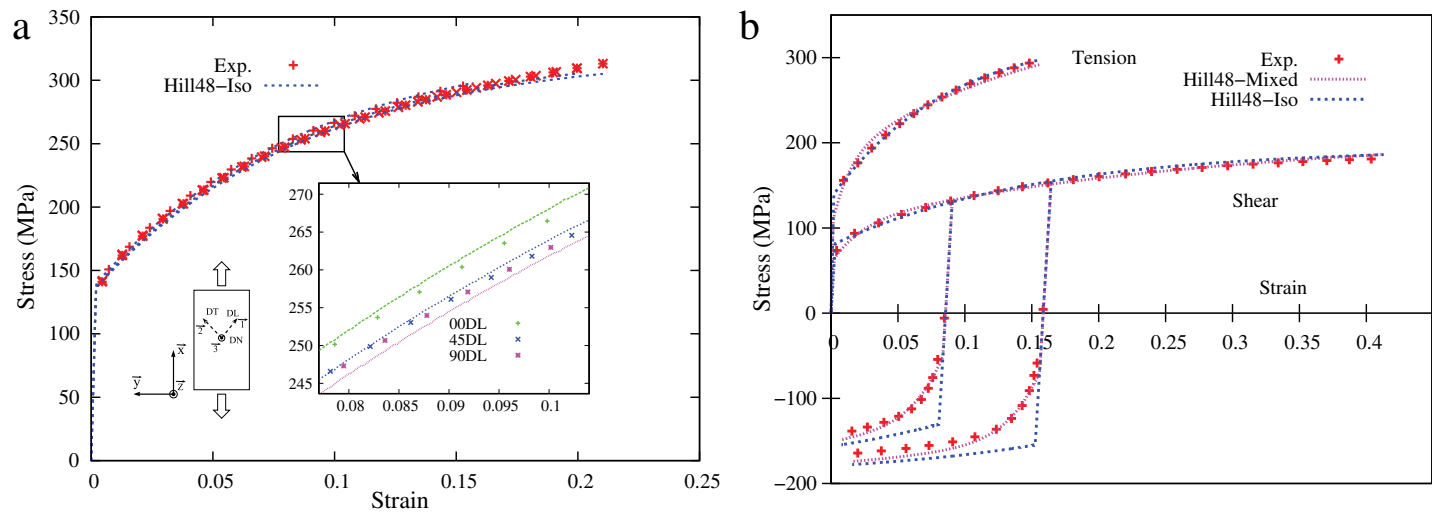

Fig. 1. (a) Tensile tests and identification at $0^{\circ}, 45^{\circ}$ and $90^{\circ}$ to RD and (b) tensile and shear tests and identification of the different models for AA6016 aluminium alloy.
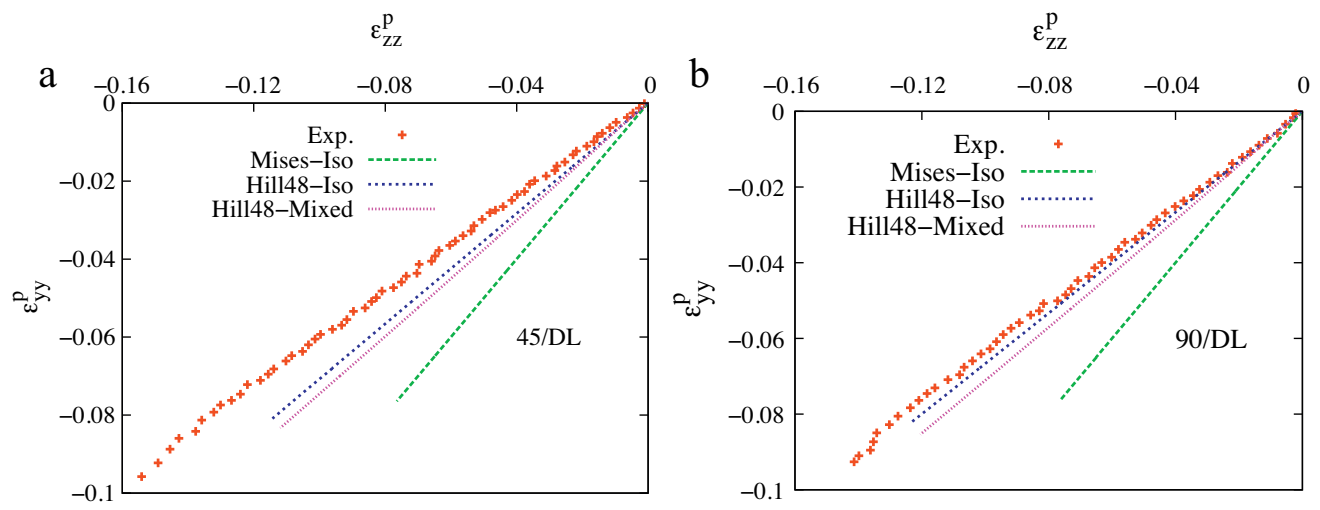

Fig. 2. Experimental thickness strain evolution in function to the transverse strain and tensile identification at (a) $45^{\circ}$ to RD and (b) $90^{\circ}$ to $R D$ for $A A 6016$ aluminium alloy. See Fig. 1a for the definition of $\vec{y}$ and $\vec{z}$ directions.

Table 2

Coefficients identified for AA6016 aluminium alloy for the different models ( $G+H=2, L=M=3$ for Hill's 1948 criterion).

\begin{tabular}{|c|c|c|c|c|c|c|c|c|}
\hline & $\sigma_{0}(\mathrm{MPa})$ & $Q$ (MPa) & $b$ & $Q_{x}(\mathrm{MPa})$ & $b_{\mathrm{x}}$ & $F$ & G & $N$ \\
\hline Mises-Iso & 139 & 190 & 11.7 & - & - & 1 & 1 & 3 \\
\hline Hill48-Iso & 139 & 190 & 11.7 & - & - & 1.24 & 1.22 & 2.70 \\
\hline Hill48-Mixed & 109 & 178 & 6.19 & 5929 & 81 & 1.31 & 1.20 & 2.89 \\
\hline
\end{tabular}

$80 \mathrm{~mm} \mathrm{~s}^{-1}$. Moreover, the roller revolution axis remains perpendicular to radius $E_{s t}$.

\section{Numerical simulations}

The numerical simulations of roller hemming were done with the finite-element code Pamstamp2G. Given the multi-operation character of the process, the numerical simulations include several successive steps, as can be seen in Fig. 6.

The numerical simulations were done with Belytschko-type finite elements. Although the Mindlin-Reissner hypotheses used for their formulation are not satisfied, Le Maoût et al. (2010) showed that these elements still make it possible to obtain good results. The number of through-thickness integration points is set to 5 . The a

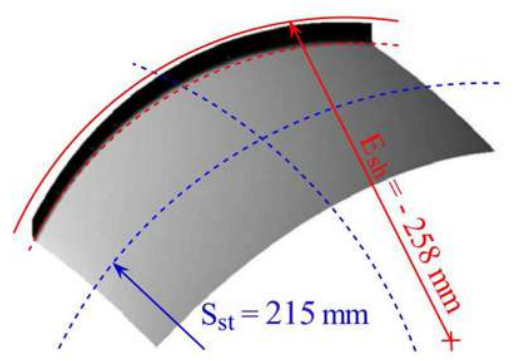

b Measurement sections

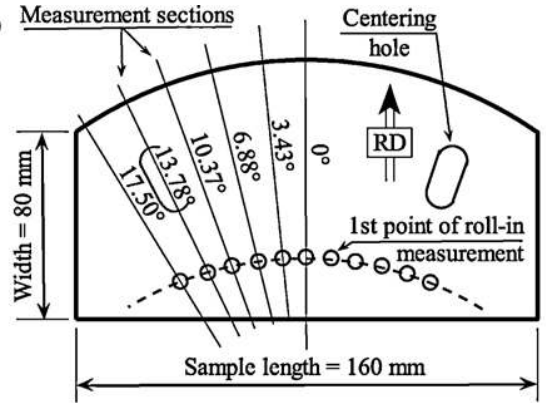

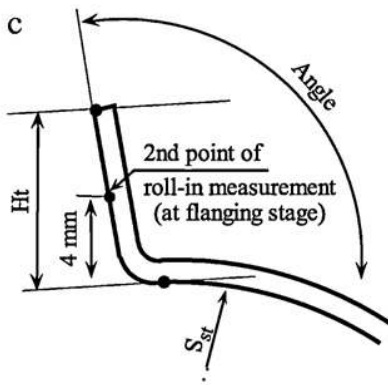

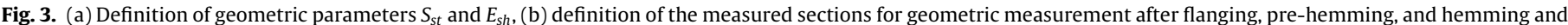

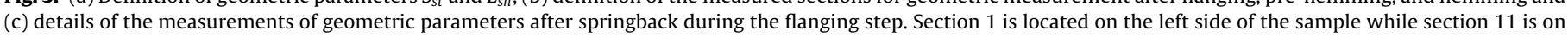
the right side, both for an angle of $17.50^{\circ}$ to the $\mathrm{RD}$. 

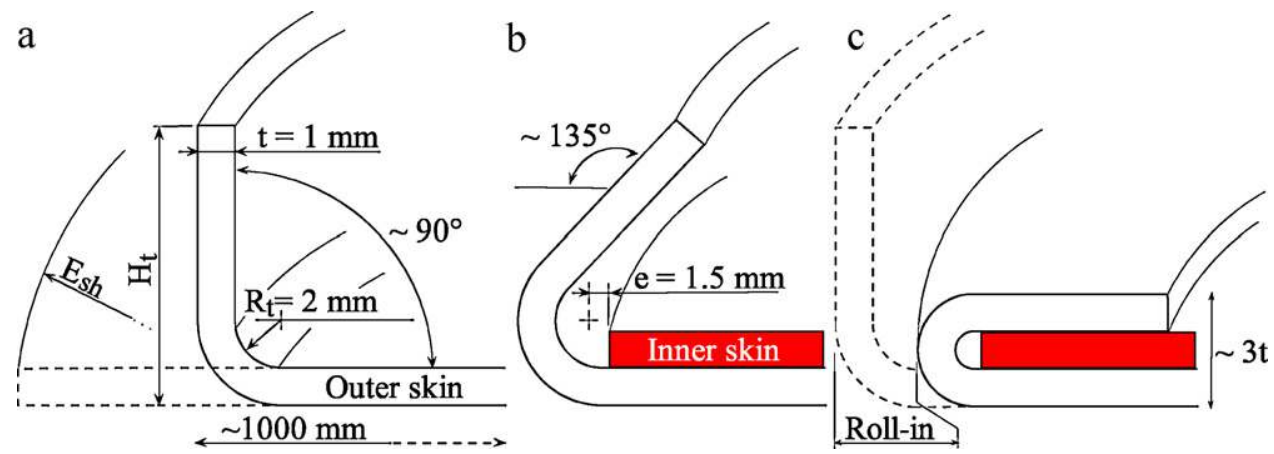

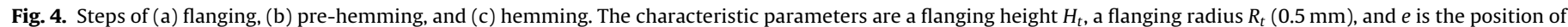
the inner part. Here, outer and inner parts have the same thickness $t$.
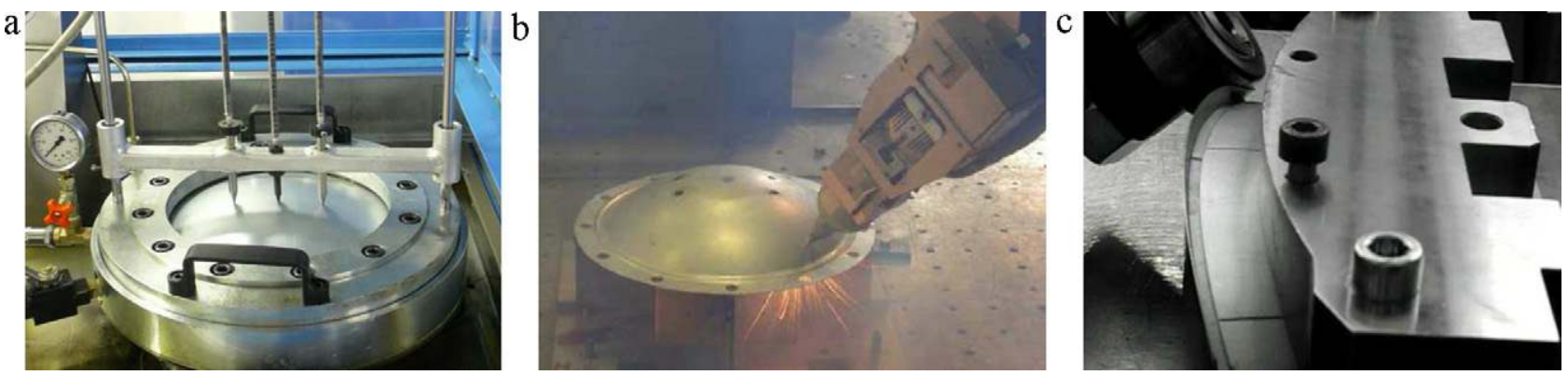

Fig. 5. (a) Biaxial expansion giving the sample curved surface, (b) laser trimming and (c) roll hemming set up.

adaptive algorithm of Pamstamp2G mesh is used, as well as two criteria to subdivide an element. The first criteria are determined by the angle between the normal to the element and that of its neighboring elements, set at a maximum of $10^{\circ}$. The second deals with the detection of the blank being closer to the tool area with high local curvature. This criterion triggers significant refining of the flanging radius area when the blank is in contact with the die radius in order to prepare for the pre-hemming and hemming steps.

\subsection{Biaxial expansion, trimming and flanging stages}

Simulation of the biaxial expansion test was done by considering half of the blank (Fig. 6). Only one blank symmetry is used so as to extract the whole sample during trimming. Indeed, simulation of the roller hemming process requires the use of the entire sample as the problem has neither geometrical nor loading symmetry. Pressure is applied to the surface of the outer part in contact with oil. The evolution of the pressure in function of time is obtained experimentally. The blank-holder force and the friction coefficient are adjusted to $600 \mathrm{kN}$ and 0.12 respectively in order to be closer to the experimental displacement evolution at the pole. At the end of the test, the equivalent plastic strain reached at the pole is slightly lower than 0.1 . The samples are obtained by trimming blanks which have undergone biaxial expansion according to the same experimental trimming line, and by keeping the elements located within the line. The elements located on the edge of the sample are refined. Intermediate springback is carried out between each step through implicit calculation. For the flanging step, the friction coefficient adopted to model the contact between the blank and the tool is 0.12 . Numerically, the sample was placed in the die and adjusted to perfectly correspond to the flanging height $\left(H_{t}\right)$ values obtained experimentally at $9 \mathrm{~mm}$ on average along the sample. The gap between the blade and the flanging die equals the thickness of the initial sheet increased by $10 \%$. The flanging blade displacement rate is imposed by a linear ramp, starting at a null rate and finishing at a constant rate of $5 \mathrm{~m} \mathrm{~s}^{-1}$ after a displacement of $1 \mathrm{~mm}$. During this step and the subsequent ones, the blank-holder force is set to $93 \mathrm{kN}$.

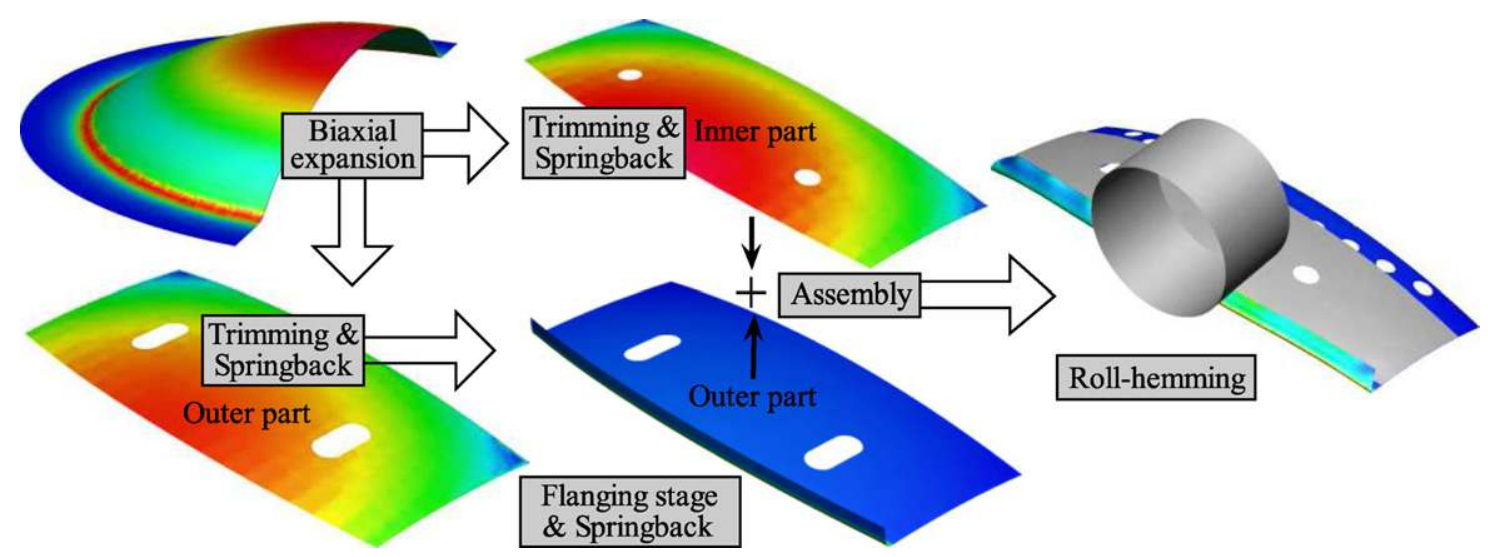

Fig. 6. Finite element calculation flow chart for samples with curved surfaces (isovalues correspond to the distribution of the equivalent plastic strain). 


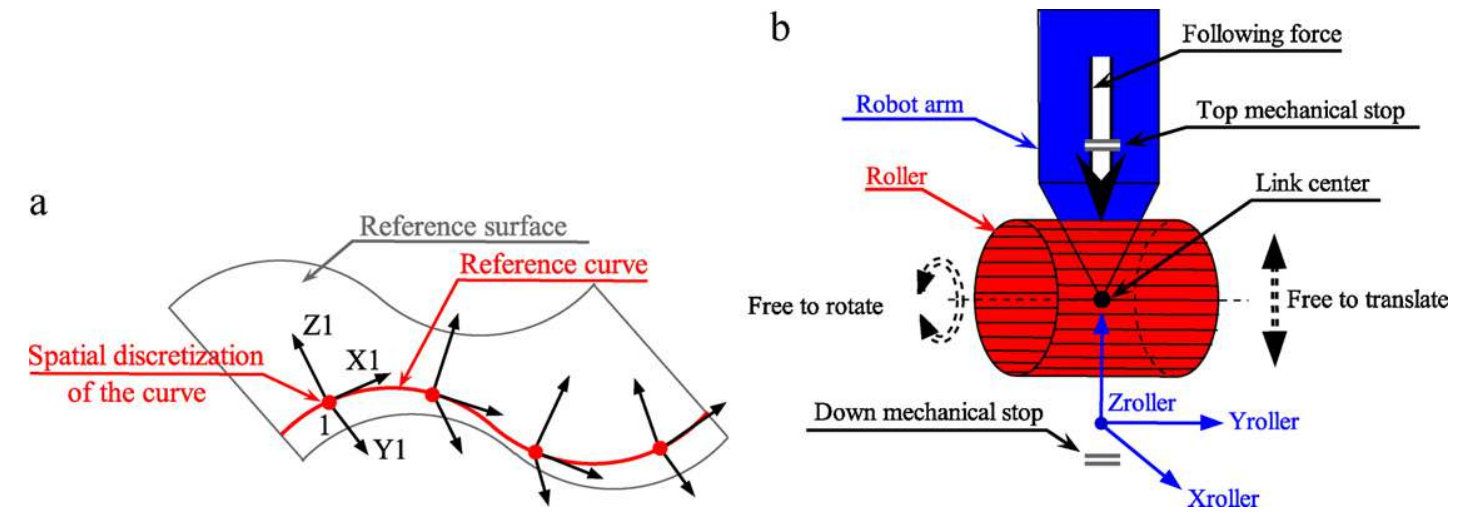

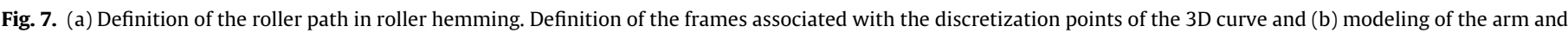
roller.

Before biaxial expansion, the element size in the future bending zone is $8.3 \mathrm{~mm}$. Element refinement is allowed since the flanging step and the element size is equal to $0.25 \mathrm{~mm}$ at the end of flanging, which corresponds to 16 elements in the final curvature radius area. The elements that are located on the edge of the sample are of small dimensions, and as their influence on the process is rather weak, a mass scaling is applied to these elements in order to decrease the calculation time. The weighting coefficient is calculated in order to correspond to the mass of an element with a characteristic length of $0.16 \mathrm{~mm}$. Several studies, such as Lange et al. (2005), have shown that this parameter has only a weak influence on the prediction of roll-in but decreases significantly the calculation time.

\subsection{Roller hemming process}

To define the roller path, a 3D curve is discretized on the piece to be hemmed. A local frame is attached to each point, which defines the direction of the roller during hemming (Fig. 7a). The displacement of the roller is performed by successively superposing the robot frame with the frame of each point of the discretized curve (Fig. 7b). The robot is constituted of a roller and an arm, the numerical link between the two parts enables free translation of the roller in direction $\vec{Z}_{\text {roller }}$ of the frame combined with free rotation around axis $\vec{X}_{\text {roller }}$. The other relative degrees of freedom between the roller and the robot arm are set, the rotation of the roller around its axis is generated by the friction force between the roller and the sheet. A follower force is applied according to direction $\vec{Z}_{\text {roller }}$ to simulate the action of the spring located between the roller and the arm. Its intensity corresponds to the experimental values taken from the sensor at the top of the robot. Moreover, the path and directions of the lowering and raising of the roller are modeled in accordance to the experimental protocol. At the beginning of the pre-hemming, the roller is set on the die edge and bend the edge of the sample near section 1 (see Fig. 3b). This lowering of the roller is performed along the normal to the die surface. It moves up at the end of the hemmed line, on the opposite side. For the hemming step, the lowering of the roller is carried out identically, but starting on the opposite side of the lowering of the roller during pre-hemming, i.e. near section 11. The friction coefficient between the roller and the sheet is taken as equal to 0.12 , the value of which is experimentally determined by averaging the results obtained for several sample geometries according to Le Maoût et al. (2010).

Acceleration of the robot arm is slight and tool inertia is negligible which justify considering the process as quasi-static. However, as modeling this process implies high non-linearity due to the material and friction contact, the equilibrium equations are solved with an explicit scheme. The stability of the solution is checked to ensure that the conditions of data generation are close to those of a quasi-static solution. The classic criterion consists in verifying that the kinetic energy stays below $5 \%$ of the internal strain energy. It should be noted that the influence of the strain rate is not taken into account here. Indeed, a preliminary numerical study has shown that a rate set at $5 \mathrm{~m} \mathrm{~s}^{-1}$ to obtain low kinetic energy (around $4 \%$ of internal energy) leads to a stable solution, unlike higher rates.

\section{Results and discussion}

Based on the work of Li et al. (2011), the longitudinal strain during roller hemming of straight samples is weak, because it always remains under $10 \%$ of the circumferential strain in the hemmed zone. Therefore, this component of the strain tensor should have only a weak influence on the roll-in value and has not been investigated here. However, in the case of curved samples, the variation of the longitudinal strain along the edge may emphasize the wrinkling and could have a larger influence on the roll-in value.

\subsection{Preliminary steps}

Fig. 8 shows the evolution of stress $\sigma_{Y Y}$ in function to strain $\epsilon_{Y Y}$ after the flanging process for three integration points in the local frame of an element situated on the symmetry plane of a sample in the bent area. The integration points are such that 1 is the closest to the internal surface to which the pressure is applied, 2 is on the median surface, and 3 is closest to the external surface. The stress evolution was noted to alternate between the biaxial expansion

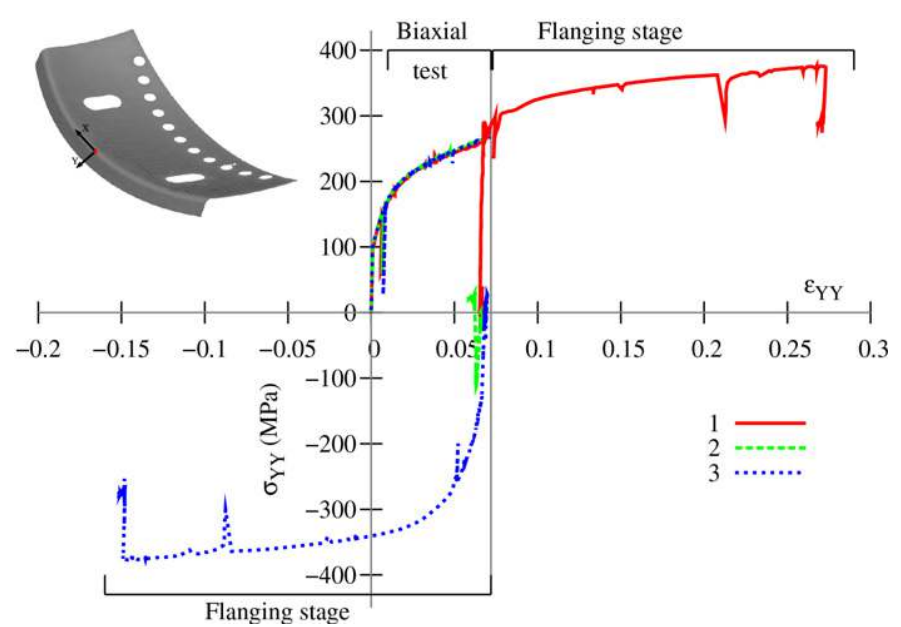

Fig. 8. Evolution of stress $\sigma_{Y Y}$ in function to strain $\epsilon_{Y Y}$ for the Hill48-Mixed model during biaxial expansion and flanging for 3 integration points in the thickness. 


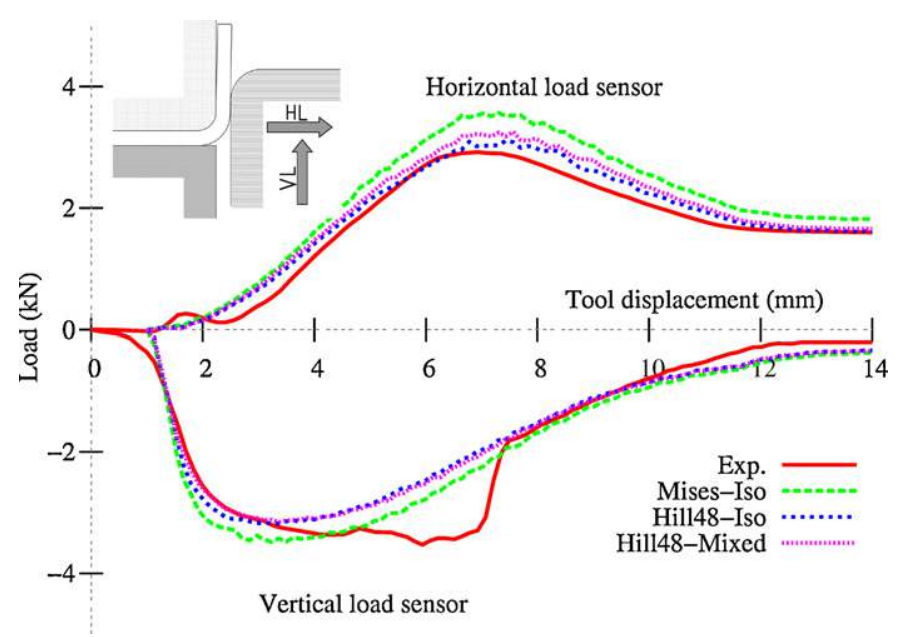

Fig. 9. Evolution of horizontal and vertical load components on the blade during flanging.

step and the flanging step for integration point 3, which justifies the use of Hill48-Mixed model.

Fig. 9 gives the evolution of horizontal and vertical load components on the blade during flanging. The rate of the vertical force-displacement curve has the characteristics of the one usually seen for flanging, see Livatyali and Altan (2001) and Muderrisoglu et al. (1996) for example. The increase of the load component at the beginning of the curve corresponds to the bending of the sheet against the flanging die radius, while inversely, the load decreases when the flanged edge comes closer to the die. Finally, the residual load at the end of flanging is caused by the sliding of the blade along the folded sheet. It can be noted that the predicted flanging load evolution is little influenced by the models used. Load amplitude is highest with Mises-Iso model which does not correlate as well with the experimental values. The results obtained with Hill48-Iso and Hill48-Mixed models are very close, despite the occurrence of cyclic loading between the biaxial expansion and flanging. The influence of anisotropy is thus preponderant in this case.

\subsection{Roller hemming}

Fig. 10 compares the beginning of the pre-hemming of the sheet during the experimental test and the numerical simulation. It was noticed that the simulation contained wrinkling similarities in terms of number and amplitude.

Figs. 11 and 12 show the roll-in evolution along the measured sections of the sample during pre-hemming and then hemming.

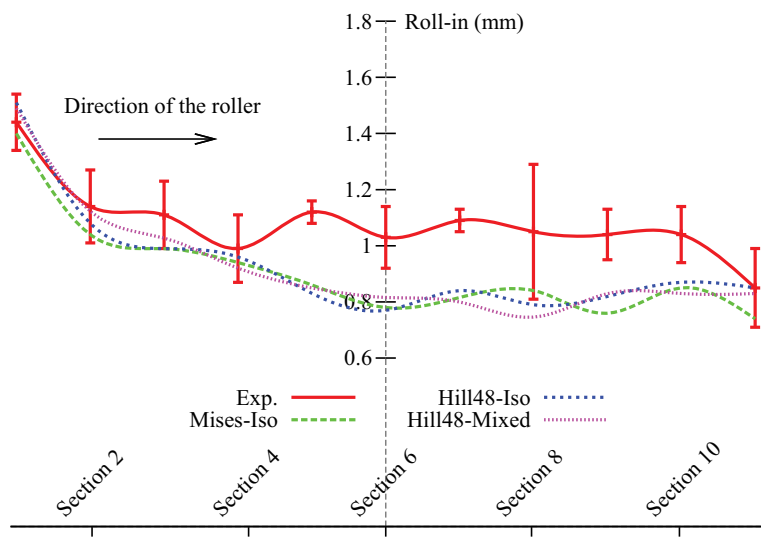

Fig. 11. Experimental and predicted roll-in values during pre-hemming.

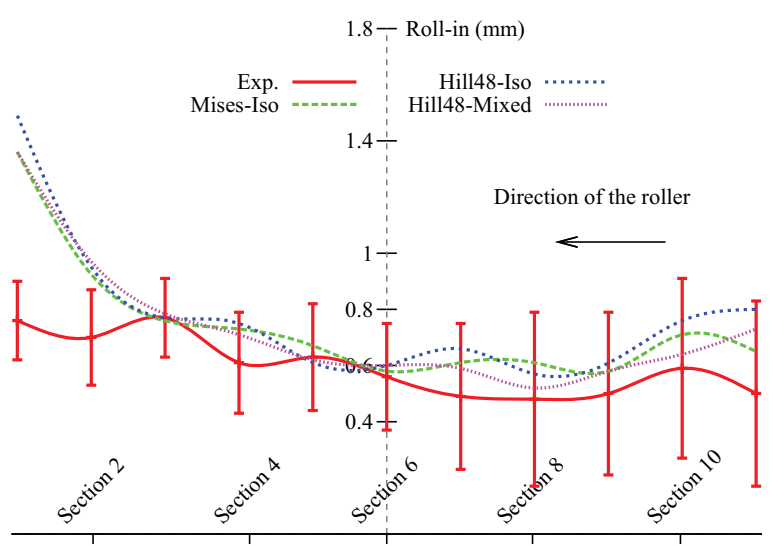

Fig. 12. Experimental and predicted roll-in values during hemming.

The experimental roll-in value is relatively stable over the length of the sample with nonetheless significant variations at the edges of the sample which corresponds to areas where the roller was lowered. Passage of the roller in the opposite direction during hemming does not, however, completely compensate for this phenomenon. Roll-in variations along the hemmed edges display the high wrinkling sensibility of this hemming technology in comparison to the classical technology. According to Livatyali et al. (2004), such sample geometry should not lead to wrinkles in classical hemming. Conversely, with roller hemming, it is noticed that flanging of such shrink samples leads to severe wrinkling during pre-hemming and that these wrinkles are mostly flattened during final hemming. This wrinkling sensitivity could be explained by a non uniform

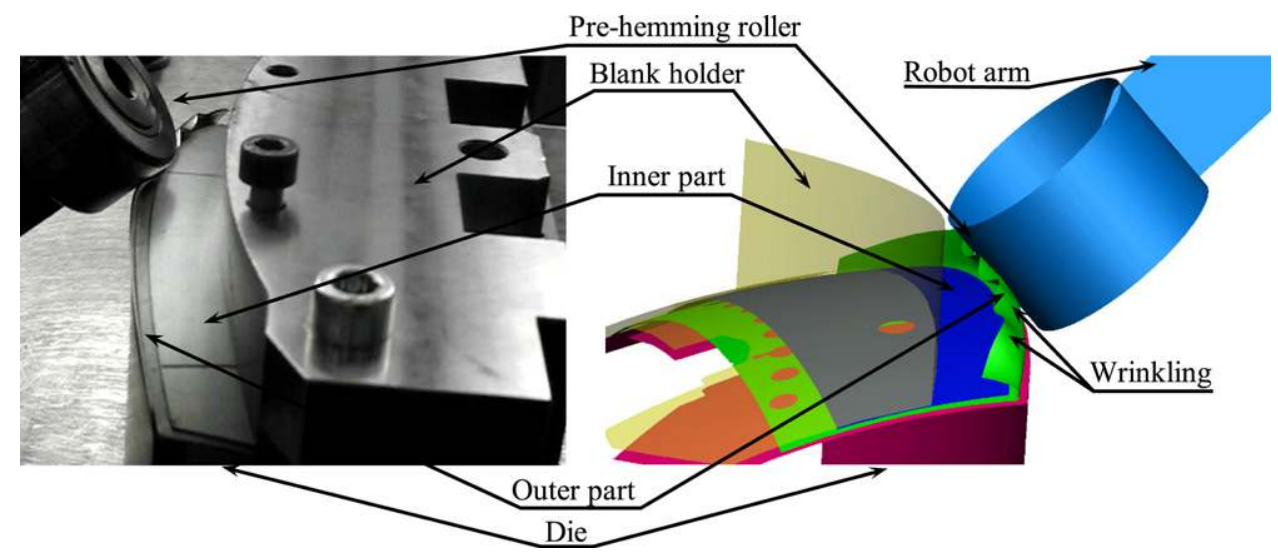

Fig. 10. Comparison of numerical simulation of pre-hemming with experiments. 


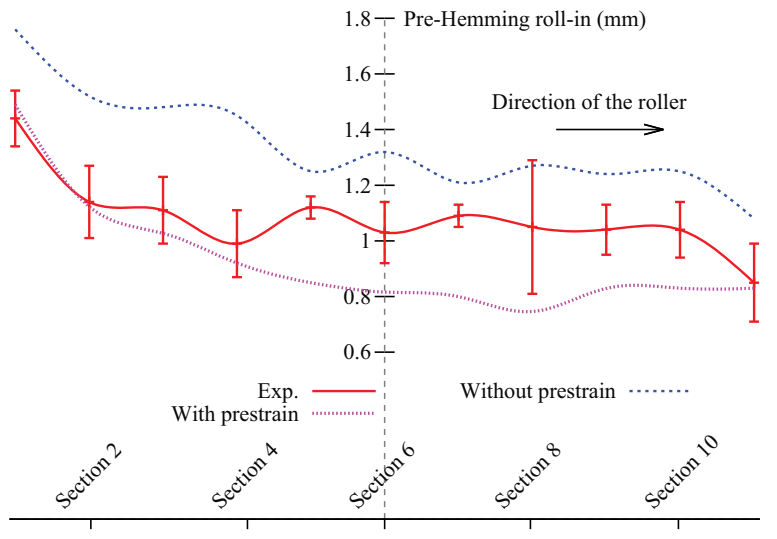

Fig. 13. Influence of the mechanical fields from the biaxial expansion and flanging steps on the prediction of roll-in during pre-hemming. Simulations are performed with Hill48-Mixed model.

distribution of the longitudinal strain that will be later investigated. The numerical results obtained for the roll-in are also provided in Figs. 11 and 12. The three constitutive models give similar results, which are close to the experimental values, except for the rollin values in sections 1 and 2 that are poorly predicted after final hemming. Even if the increase of roll-in due to the lowering of the roller is well predicted during pre-hemming, it is observed that the roll-out is overestimated after hemming. This could be linked to either a discrepancy of the roller path between experimental and numerical procedures or to a wrong predicted strain state in this region after pre-hemming. Hill48-Mixed model does not improve the results. Despite the strain path changes observed in Fig. 8, the kinematic hardening is not so significant for this material, leading to small differences in terms of roll-in whatever the model used during pre-hemming.

In the case of classical hemming, Svensson and Mattiasson (2002) demonstrated the influence of taking into account the prestrain linked to forming operations in the numerical simulation of the process. The roll-in is systematically reduced during pre-hemming by taking into account the prestrain state, but can decrease or increase if the hemmed edge is in a shrink or a stretch strain state. Here, the objective is to study this influence for roller hemming. The forming operations concerned are biaxial expansion, trimming, as well as the flanging phase. A numerical simulation was thus carried out without considering the previous operations by importing the sample mesh at the end of the flanging calculation. The refining history of the mesh is kept without taking into account the stress and strain states obtained during the preliminary operations, nor the sheet thickness evolution. The goal is to obtain the approximation carried out for the simulation directly on the already flanged samples, without taking the strain history into account.

Figs. 13 and 14 show the need of taking into account the prestrain history in the numerical simulation. During pre-hemming, the roll-in is $30 \%$ overestimated when the strain history was not considered. The roll-in obtained during hemming for both simulations shows also significant gaps, of the order of $100 \%$ when prestrain is not taken into account. In fact, the plastic strain is located in the flanging radius and creates a substantially hardened area around which the sheet rolls up. Less significant roll-in is thus obtained, which has values that are closer to the experimental ones when the flanging step is taken into consideration during the numerical simulation. This justifies taking preliminary forming operations into account, notably for the prediction of wrinkling and roll-in values.

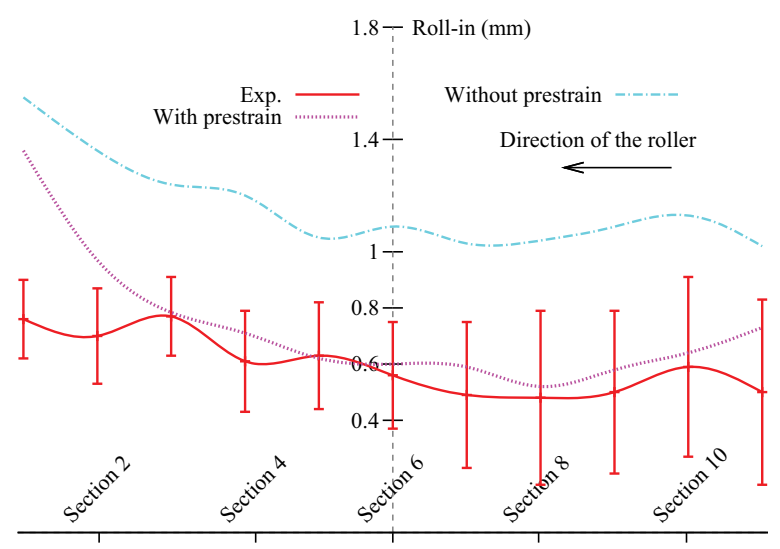

Fig. 14. Influence of the mechanical fields from the biaxial expansion and flanging steps on the prediction of roll-in during hemming. Simulations are performed with Hill48-Mixed model.

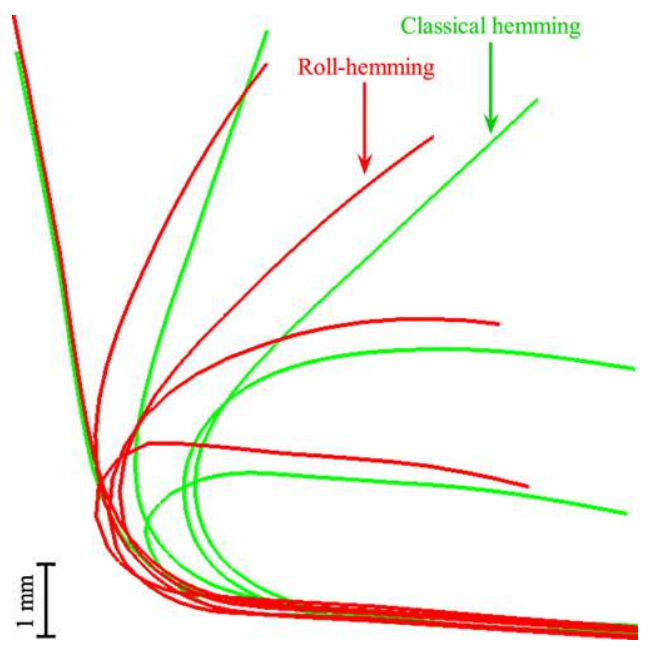

Fig. 15. Comparison of the shape of the bent medium section obtained by roller hemming and by classical hemming.

\subsection{Comparison of classical and roller hemming}

The small influence of models on roll-in prediction tends to indicate that the main factor that governs roll-in is the kinematics of the material points in the bent area. Roll-in values in classical hemming, for the same material and sample geometry, vary in between 1.3 and $1.7 \mathrm{~mm}$ and are much lower in roller hemming. Fig. 15 shows profiles extracted from numerical simulations of both processes in the center of the specimen. It can be observed that the main difference occurs during the pre-hemming step. In classical hemming, roll-in increases drastically in the pre-hemming step and then decreases. This phenomenon occurs only slightly in roller hemming for which there is a smooth and rather regular increase of roll-in during the pre-hemming and hemming.

\section{Conclusion}

Roller hemming tests were carried out for aluminium alloy samples with a curved geometry having both a curved surface and an in-plane curved edge. The samples were prestrained by biaxial expansion to obtain a strain history before flanging and hemming. The choice of the geometry studied and the imposed prestrain before flanging comes from the study of geometries which cause problems during hemming for opening parts of automobiles. The main results are: 
- the experimental characterization of the aluminium alloy AA6016, done through tensile and simple shear tests, has shown that the material has a low variation of the flow stress in the sheet plane, as well as only a slight Bauschinger effect. The identification of an anisotropic elastic-plastic mixed-hardening model has nevertheless given the best description of the mechanical behavior.

- the numerical simulation shows good correlation of the wrinkles which appear on the samples during pre-hemming. The fact of taking into account the anisotropy and Bauschinger effect of the material has little influence on the roll-in prediction. It has been shown that the strain history, linked to the preliminary forming operations, significantly increases roll-in during pre-hemming, as well as the appearance of wrinkles on the edge of the sample. It is therefore essential to integrate all of the preliminary steps into the numerical simulation of roller hemming.

- the order of magnitude of roll-in in classical and roller hemming is different (around $1.5 \mathrm{~mm}$ in classical and $0.6 \mathrm{~mm}$ in roller hemming) that comes mainly from a more regular movement of the material points located in the bent area in roller hemming than in classical hemming.

\section{References}

Armstrong, P.J., Frederick, C., 1966. Mathematical representation of the multiaxial Bauschinger effect. Technical report of the Central Electricity Generating Board, $\mathrm{RD} / \mathrm{B} / \mathrm{N} 731$.

Bochud, N., Alves, J.L., Oliviera, M.C., Menezes, L.F., 2008. Constitutive parameters identification of advanced yield criteria from a reduced base of experimental results. In: Proceedings of the 7th International Conference and Workshop on Numerical Simulation of 3D Sheet Metal Forming Processes (Numisheet), Interlaken, Switzerland, 1-5 September, pp. 79-84.

Chaparro, B.M., Thuillier, S., Menezes, L.F., Manach, P.Y., Fernandes, J.V., 2008. Material parameters identification: gradient-based, genetic and hybrid optimization algorithms. Computational Material Science 44 (2), 339-346.

Gallée, S., Manach, P.Y., Thuillier, S., 2007. Mechanical behavior of a metastable austenitic stainless steel under simple and complex loading paths. Materials Science and Engineering A 466 (1-2), 47-55.

Grolleau, V., Gary, G., Mohr, D., 2008. Biaxial testing of sheet materials at high strain rates using viscoelastic bars. Experimental Mechanics 48 (3), 293-306.

Hill, R., 1948. A theory of the yielding and plastic flow of anisotropic metals. Proceedings of the Royal Society of London, A 193, 281-297.
Hu, Z., Lin, Z.Q., Zhao, Y.X., 2010. Fracture limit prediction for roller hemming of aluminium alloy sheet. Materials and Design 31 (3), 1410-1416.

Iwata, N., Matsui, M., Nakagawa, N., Ikura, S., 1995. Improvements in finite-element simulation for stamping and application to the forming of laser-welded blanks. Journal of Materials Processing Technology 50 (1-4), 335-347.

Lange, C., Felder, E., Massoni, E., Auger, P., Kanji Nanji, A., 2005. Hemming simulations with different element formulations and material models. In: International Deep Drawing Research Group (IDDRG) Conference, Besançon, France, 20-22 June.

Lange, C., 2008. Sertissage à plat pour la carrosserie automobile: simulation numérique. Techniques de l'ingénieur BM 7 866, 1-19.

Le Maoût, N., Thuillier, S., Manach, P.Y., 2009. Aluminium alloy damage evolution for different strain paths-application to hemming process. Engineering Fracture Mechanics 76 (9), 1202-1214.

Le Maoût, N., Thuillier, S., Manach, P.Y., 2010. Classical and roll-hemming processes of pre-strained metallic sheets. Experimental Mechanics 50 (7), 1087-1097.

Le Maoût, N., Thuillier, S., Manach, P.Y., 2010. Drawing, flanging and hemming of metallic thin sheets: a multi-step process. Materials and Design 31 (6), 2725-2736.

Li, S., Hu, X., Zhao, Y., Lin, Z., Xu, N., 2011. Cyclic hardening behavior of roller hemming in the case of aluminium alloy sheets. Materials and Design 32 (4), 2308-2316.

Livatyali, H., Müderrisoğlu, A., Ahmetoğlu, M.A., Akgeman, N., Kinzel, G., Altan, T. 2000. Improvement of hem quality by optimizing flanging and pre-hemming operations using computer aided die design. Journal of Materials Processing Technology 98 (1), 41-52.

Livatyali, H., Altan, T., 2001. Prediction and elimination of springback in straight flanging using computer aided design methods. Part I. Experimental investigations. Journal of Materials Processing Technology 117 (1-2), 262-268.

Livatyali, H., Laxhuber, T., Altan, T., 2004. Experimental investigation of forming defects in flat surface-convex edge hemming. Journal of Materials Processing Technology 146, 20-27.

Muderrisoglu, A., Murata, M., Ahmetoglu, M.A., Kinzel, G., Altan, T., 1996. Bending, flanging and hemming of aluminium sheet-an experimental study. Journal of Materials Processing Technology 59 (1-2), 10-17.

Svensson, M., Mattiason, K., 2002. The influence on the roll-in in hemming. A comparison between FE-simulations and practical tests. In: 5th International Conference and Workshop on Numerical Simulation of 3D Sheet Metal Forming Process (Numisheet), Jeju Island, South Korea, 21-25 October.

Svensson, M., Mattiasson, K., 2002. Three-dimensional simulation of hemming with the explicit FE-method. Journal of Materials Processing Technology 128 (1-3), $142-154$.

Thuillier, S., Le Maoût, N., Manach, P.Y., Debois, D., 2008. Numerical simulation of the roll hemming process. Journal of Materials Processing Technology 198 (1-3), $226-233$.

Thuillier, S., Manach, P.Y., 2009. Comparison of the work-hardening of metallic sheets using tensile and shear strain paths. International Journal of Plasticity 25 (5), 733-751.

Thuillier, S., Le Maoût, N., Manach, P.Y., 2011. Influence of ductile damage on the bending behavior of aluminium alloy thin sheets. Materials and Design 32 (4), 2049-2057. 